\title{
Prospect Analysis of High Frequency Inverter Used in ESP
}

\author{
Bangzhong Han * \\ Haichen Enviromental Protection Technology Co., Ltd., Rizhao, Shandong 276800, China
}

\begin{abstract}
It has been difficult for the old ESP to meet the new dust emission standards, and the update of the equipment costs a lot of money, therefore, how to reach a higher cost performance becomes the focus of attention. After researches we found that the replacement of the industrial frequency power with the high-frequency inverter of the ESP power can greatly improve the collection efficiency, with a high cost performance and a good prospect of application. The core idea of electrostatic precipitators of high frequency inverter is to transfer three-phase working frequency power into DC power, make use of modernized power electronic technologies and transfer DC power inverter into high frequency AC for control. We can see from this article that electrostatic precipitators of high frequency inverter enjoy the following strengths: (l) Threephase rectifier transfers three-phase AC power into DC power; the inverter transfers $\mathrm{DC}$ voltage into high frequency $\mathrm{AC}$ voltage. This method enjoys great flexibility in the control. (2) The output form of high frequency AC voltage square wave in the inverter transfers step-up transformer into high frequency transformer. (3) Compared with the traditional power supply of controllable silicon working frequency phase control electrostatic precipitators, the electrostatic precipitators power supply of high frequency inverter adopts full-controllable power component: IGBT which features swift switchon/off speed and in case of flashover in the electrostatic precipitators, it is switched off immediately. Research has discovered that high frequency inverter can greatly upgrade the dust collection efficiency, enjoy favorable advancement and very high performanceprice ratio and realize broad application prospect.
\end{abstract}

\section{KEYWORDS}

High-frequency inverter

ESP

Power optimization

Energy saving and emission reduction

\section{Introduction}

The electrostatic precipitators (ESP) make use of power to separate dust from the gas and thus greatly reduces the smoke dust volume exhausted into the atmosphere; it is an important environment-friendly equipment in improving the environment and upgrading air quality. In China, electrostatic precipitators are collocated in the power plants, coal-fired boilers, alkali recovery boilers, cement plants,

Copyright $\odot 2015$ Bangzhong Han

doi: $10.18686 /$ esta.v2i1.2

Received: October 10, 2015; Accepted: November 3, 2015; Published online: December 3

This is an open-access article distributed under the terms of the Creative Commons Attribution Unported License (http://creativecommons.org/ licenses/by-nc/4.0/), which permits unrestricted use, distribution, and reproduction in any medium, provided the original work is properly cited.

${ }^{*}$ Corresponding author: Haichen Enviromental Protection Technology Co., Ltd., Rizhao, Shandong 276800, China. E-mail: hbz6419@139.com rubbish power plants, non-ferrous metallurgical industry and iron \& steel industry. It is featured as high dust collection efficiency, small resistance losses, high temperature resistance, large smoke treatment volume and high degree of automation; the product is widely applied.

China's coal consumption volume takes up above $60 \%$ of total energy consumption volume; therefore, smoke dust and $\mathrm{SO}^{2}$ pollution is becoming increasingly serious. In 1980s-1990s, the electrostatic precipitators suffered from poor environmental protection property and small design margin; it requires for immediate updating. The power supply of electrostatic precipitators is a key equipment in the electric dust collection system and an important energy consumption equipment. Upgrading the efficiency of power supply of electrostatic precipitators has become the most effective method to upgrade the efficiency of electrostatic precipitators and meet the new national standard in environmental protection. 


\section{Theories and features of high frequency inverter power supply}

The core idea of electrostatic precipitators of high frequency inverter is to transfer three-phase working frequency power into DC power; make use of modernized power electronic technologies and transfer DC power inverter into high frequency $\mathrm{AC}$ for control. The topological form of high frequency inverter is shown in Figure 1.

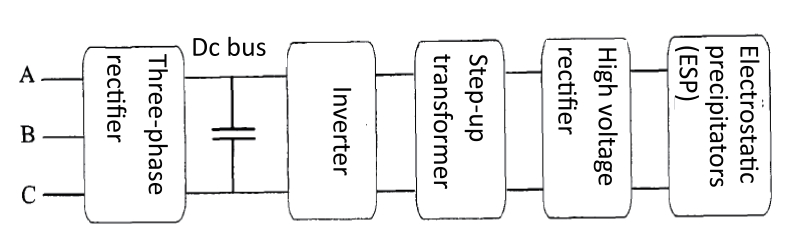

Figure 1. Block diagram of electrostatic precipitator power supply of high frequency inverter.

It mainly enjoys the following features:

(1) Three-phase rectifier transfers three-phase AC power into DC power; the inverter transfers DC voltage into high frequency $\mathrm{AC}$ voltage. This method enjoys great flexibility in the control; it is mainly demonstrated in numerous control methods and their combination, such as PWM (pulse width modulation), PS-PWM (phase-shift pulse width modulation), PDM (pulse density modulation) and PFM (pulse frequency modulation). Given high frequency control model, the output voltage has a small ripple wave, system enjoys a swift dynamic response speed and dust collection efficiency is obviously upgraded. Besides, the electrostatic precipitator power supply of high frequency inverter is able to produce specific high-voltage output wave form given flexible control to adapt to different dust collection conditions [1].

(2) The output form of high frequency AC voltage square wave in the inverter transfers step-up transformer into high frequency transformer. Under the condition of unchanged voltage increase ratio, the high/low-voltage winding quantity of high frequency transformer is obviously reduced compared with the working frequency transformer.
The volume of transformer is obviously reduced; raw materials such as transformer winding copper, oil tank's iron and insulating oil are greatly reduced. The weight of power supply of high frequency electrostatic precipitators is only about $1 / 5$ of the traditional power supply of working frequency electrostatic precipitators.

(3) Compared with the traditional power supply of controllable silicon working frequency phase control electrostatic precipitators, the electrostatic precipitators power supply of high frequency inverter adopts full-controllable power component: IGBT which features swift switch-on/ off speed, and in case of flashover in the electrostatic precipitators, it is switched off immediately. The said features realize better properties than the power supply of working frequency electrostatic precipitators. The power supply of traditional working frequency electrostatic precipitators has a power factor of about 0.7 and working efficiency of about $75 \%$. However, the electrostatic precipitator power supply of high frequency inverter has a power factor of above 0.9 and working efficiency of above $95 \%$ : It enjoys obvious energy-saving effect [3].

\section{Advancement analysis of electrostatic precipita- tors of high frequency inverter \\ 3.1. Contrast of typical stable output wave form}

Larger output current and voltage of the power supply lead to better dust collection efficiency. However, the working voltage of electrostatic precipitators is restricted to the said limit by the flashover voltage; therefore, larger output current of electrostatic precipitators power supply leads to higher dust collection efficiency under the same flashover voltage. Figure 2 demonstrates the contrast of typical wave form between high frequency inverter' electrostatic precipitators power supply under stable operation and working frequency electrostatic precipitators's power supply.

We can conclude from the said figure that output voltage of working frequency electrostatic precipitators' power supply has rather large ripple wave; if the flashover voltage is about $80 \mathrm{kV}$, the average output voltage is about $60 \mathrm{kV}$ which is only $75 \%$ of flashover voltage. However, the output voltage of high frequency electrostatic precipitators'
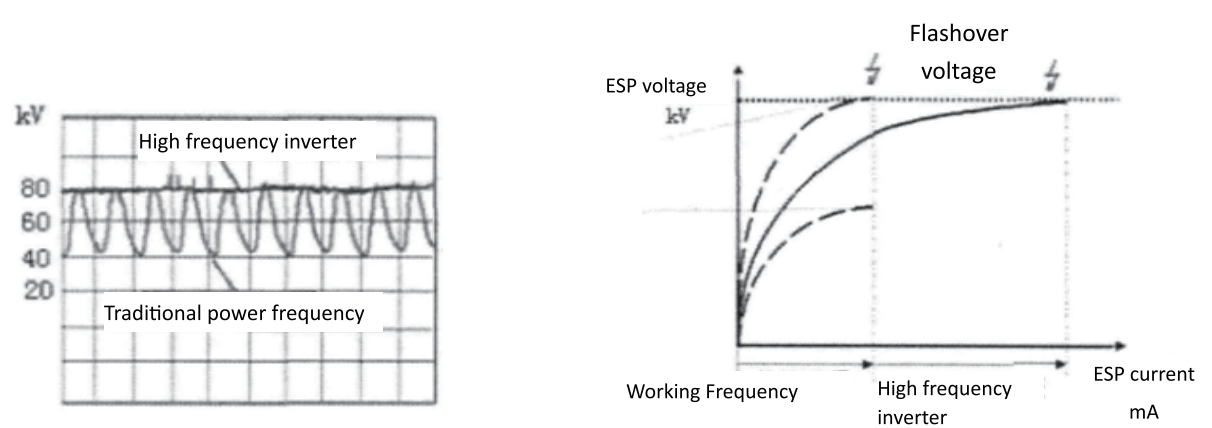

Figure 2. Contrast of typical wave form between high frequency inverter' electrostatic precipitators power supply under stable operation and working frequency electrostatic precipitators' power supply. 
power supply is rather stable and similar to the flashover voltage. Therefore, the electrostatic precipitator power supply of high frequency inverter enjoys larger current output ability and higher dust collection efficiency $[2,4]$.

\subsection{Contrast of dynamic output wave form}

The electrostatic precipitator power supply of high frequency inverter not only enjoys outstanding strength in stability, but also enjoys strength in the dynamic properties. Figure 3 demonstrates the typical contrast wave form between electrostatic precipitators power supply of high frequency inverter and power supply of working frequency electrostatic precipitators in the flashover and restart.
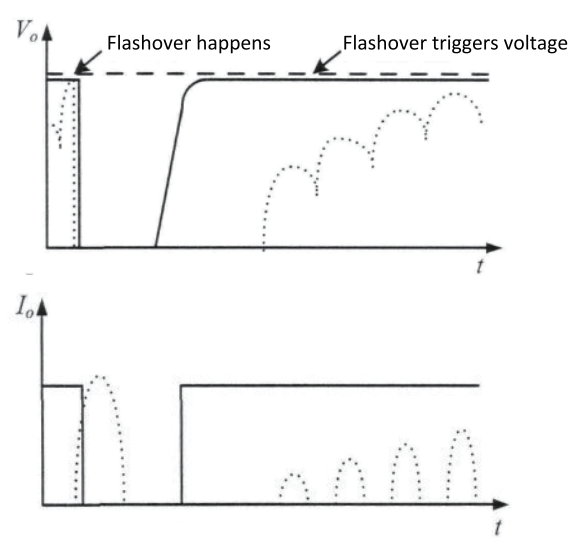

Figure 3. The typical contrast wave form between electrostatic precipitators power supply of high frequency inverter and power supply of working frequency electrostatic precipitators.

We can see from the said figure that both output voltages are reduced obviously in the flashover; the difference lies in that electrostatic precipitator power supply of high frequency inverter can swiftly respond and seal up power output; therefore, the output current is reduced swiftly to zero. Since the power supply of working frequency electrostatic precipitators cannot immediately switch off the thyristor so that output current suffers from over-current and takes a long time to gradually reduce to zero, a huge amount of energy is consumed in the electrostatic precipitators and great impact is triggered against the power supply.

We can conclude from Figure 3 that electrostatic precipitators power supply of high frequency inverter has a short flashover time; the system is restarted upon short deionizing time; since electrostatic precipitators power supply of working frequency inverter has a long flashover time, spark discharge is serious and electrostatic precipitators produces a huge amount of space power load; therefore, a rather long deionizing time is required to restart the system. In the system restart, the electrostatic precipitators power supply of high frequency inverter has a swift response speed, the output voltage can swiftly reach the preset voltage; however, the electrostatic precipitators power supply of working frequency inverter requires for numerous working frequency cycles. The said two aspects reveal that effective dust collection time of electrostatic precipitator power supply of high frequency inverter is higher than that of electrostatic precipitators power supply of working frequency inverter and enjoys higher dust collection efficiency [5].

\section{Application example of high frequency power supply}

Table 1 offers the on-site data of dust exhaust volume relative to the electrostatic precipitator power supply of traditional working frequency inverter upon application of electrostatic precipitators power supply of high frequency inverter in various industries.

We can conclude from Table 1 that electrostatic precipitator power supply of high frequency inverter enjoys obvious exhaust reduction effect of dust: Average 50\%.

\section{Conclusion}

The core idea of electrostatic precipitators of high frequency inverter is to transfer three-phase working frequency power into DC power; make use of modernized power electronic technologies and transfer DC power inverter into high frequency AC for control. We can see from this article that electrostatic precipitators of high frequency inverter enjoy the following strengths: (1) Three-phase rec-

Table 1. Exhaust reduction data upon application of electrostatic precipitator power supply of high frequency inverter in various industries.

\begin{tabular}{cccc}
\hline Applications & Area & $\begin{array}{c}\text { Quantity of units installed with electrostatic } \\
\text { precipitator power supply of high frequency } \\
\text { inverter (entity) }\end{array}$ & $\begin{array}{c}\text { Reduction ratio of } \\
\text { exhaust volume }\end{array}$ \\
\hline $\begin{array}{c}\text { Coal-fired boiler } \\
\text { Alkali recovery furnace }\end{array}$ & Various areas of the world & 195 & $\sim 60 \%$ \\
Humid electrostatic precipitators & Baltic, Canada, South America & 143 & $40-60 \%$ \\
Cement and lime & Various areas of the world & 103 & $40-85 \%$ \\
Rubbish & Europe & 95 & $\sim 75 \%$ \\
Biological boiler & Japan, Europe & 51 & $20-50 \%$ \\
Glass products & Baltic & 121 & $10-40 \%$ \\
$\sim 60 \%$ & 52 & $\sim 50$ \\
\hline
\end{tabular}


tifier transfers three-phase AC power into DC power; the inverter transfers DC voltage into high frequency AC voltage. This method enjoys great flexibility in the control. (2) The output form of high frequency $\mathrm{AC}$ voltage square wave in the inverter transfers step-up transformer into high frequency transformer. (3) Compared with the traditional power supply of controllable silicon working frequency phase control electrostatic precipitators, the electrostatic precipitators power supply of high frequency inverter adopts full-controllable power component: IGBT which features swift switch-on/off speed and in case of flashover in the electrostatic precipitators, it is switched off immediately. It can not only greatly reduce the power consumption of electrostatic precipitators, upgrade the dust collection efficiency and play a great role in saving energy, reducing exhaust volume and responding to the new exhaust standard, but also bring great convenience to the enterprise which finds it difficult to replace a huge amount of electrostatic precipitatorss. It enjoys favorable advancement and very high performance-price ratio and thus realizes broad application prospect.

\section{References}

1. Liu, Y., \& He, X. (2005). PDM and PFM hybrid control of a series-resonant inverter for corona surface treatmen. IEE Proceedings Electric Power Application, 152(6), 14051410.

2. Liu, Y., He, X. N., \& Zhang, Z. C. (2005). Research and Fabrication of Surface Treatment Power Supply of Pulse Density Modulated Serial Harmonic Type Plastic Film. China Motor Engineering Journal, 25(26), 155-162.

3. Zhang, Q. (2006). PS-PWM Control and Human-Machine Interface of Surface Treatment Power Supply of Plastic Film (master's thesis). Hangzhou: Zhejiang University.

4. Zhang, G. X., \& Jiang, Y. F. (2007). Development Direction of Power Supply of electrostatic precipitators---High Frequency and Digitalization. Power World, l, 1-4.

5. Grass, N., Hartmann, W., \& Klockner, M. (2004). Application of different types of high-voltage supplies on industrial electrostatic precipitators. IEEE Transactions on Industry Applications, 40(6), 1513-1520. 